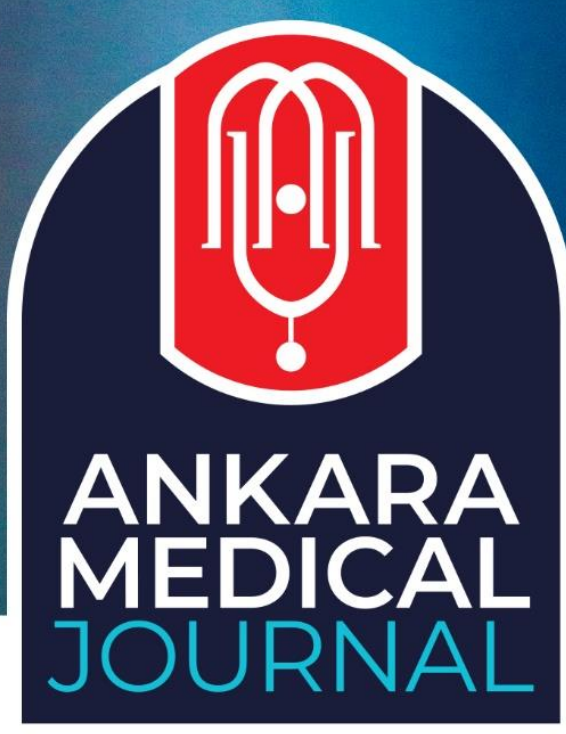

Araştırma Makalesi

Ankara Med J, 2021;(3):441-453 // 10 10.5505/amj.2021.30783

ADÖLESAN İDİYOPATİK SKOLYOZLU HASTALARDA POSTERIOR SPINAL FÜZYON VE VERTEBRA CISIMM GERDİRME CERRAHISIINIIN SONUÇLARININ VE YAŞAM KALİTESINIIN DEĞERLENDİRILMESI

\title{
OUTCOMES OF POSTERIOR SPINAL FUSION AND VERTEBRAL BODY TETHERING IN PATIENTS WITH ADOLESCENT IDIOPATHIC SCOLIOSIS AND EVALUATION OF QUALITY OF LIFE
}

(D) Altuğ Yücekul'1, (D) Gokhan Ergene ${ }^{2}$

${ }^{1}$ Acıbadem Mehmet Ali Aydınlar Üniversitesi Tıp Fakültesi, Ortopedi ve Travmatoloji AD., Türkiye ${ }^{2}$ Acıbadem Mehmet Ali Aydınlar Üniversitesi Sağlık Hizmetleri Meslek Yüksekokulu, Tıbbi Hizmetler ve Teknikler Bölümü, Ameliyathane Hizmetleri AD., İstanbul, Türkiye

Yazışma Adresi / Correspondence: Altuğ Yücekul (e-posta: ayucekul@gmail.com)

Geliş Tarihi: 26.07.2021 // Kabul Tarihi: 14.09.2021

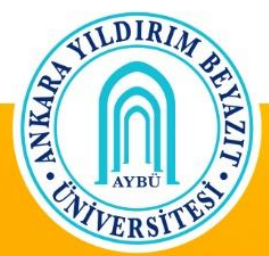

Ankara Yildırım Beyazıt University Faculty of Medicine Department of Family Medicine 


\section{Öz}

Amaç: Adölesan idiopatik skolyoz'un (AIS) cerrahi tedavisinde standart yaklaşımı posterior enstrümentasyon ve füzyon (PEF) oluşturur. Tedaviye alternatif, füzyonsuz cerrahi yöntem olan vertebra cisim gerdirme (VBT) ise giderek daha sık kullanılmaktadır. Bu çalışmayla, PEF ve VBT yöntemleri ile ameliyat edilmiş AIS hastalarının düzelme miktarları ve yaşam kalitelerinin karşılaştırılması amaçlanmıștır.

Materyal ve Metot: Eşleşmiş kohortlar, 2 yll takipli $40^{\circ}-70^{\circ}$ eğriliği olan AIS hastaları incelenerek elde edildi. Lomber eğriliğin cerrahiye dahil edildiği hastalar çalışmadan çıkartıldı. Hastaların demografik verileri, perioperatif ve takip radyografik ölçümleri ve hasta tarafından bildirilen SRS-22 skorları karşılaştıııldı.

Bulgular: Çalışmaya, 16 PEF ve 18 VBT hastası (30K, 4E) dahil edildi. Kohortun ortalama yaşı 13,4 (10-17) yll ve takip süresi 25,7 (24-32) aydı. Grupların preoperatif üst torasik, ana torasik (MT) ve torakolomber (TL) skolyoz açıları benzerdi. PEF grubunda MT eğrilikte cerrahi düzelme oranı daha fazla $(\% 84-\% 53, p<0,001)$ iken, 2. yllda toplam düzelme oranları gruplarda benzerdi $(\% 80-\% 76, p=0,616)$. 2. yllda PEF ve VBT gruplarında kendi imaj/görüşünde ve ara toplamda anlamlı iyileşme olduğu saptandı ( $<<0,001-p=0,037$ ve $\mathrm{p}<0,001-\mathrm{p}=0,016)$. PEF grubunda, fonksiyon/ aktivite alt başlığındaki skorlar 6 . ayda ve 2 . yılda $(\mathrm{p}=0,027)$ ve ağrı, ara-toplam skorları 2. yılda, VBT grubuna göre düşüktü ( $p=0,020, p=0,036)$.

Sonuç: PEF ve VBT cerrahisi takibinde MT ve TL eğriliklerde 2. yılda benzer oranda düzelme görülmektedir. SRS22 skorlarında iki cerrahi ile benzer iyileşme elde edilirken, VBT'de bu iyileşme dinamik olarak seyretmektedir. İki grup arasında fonksiyon/aktivite, ara-toplam ve ağrı skorlarının VBT grubunda erken dönem ve takipte füzyona klyasla daha iyi olması, daha uzun takipli geniş hasta serilerinde incelenmelidir.

Anahtar Kelimeler: Adölesan idiopatik skolyoz, posterior enstrümentasyon ve füzyon, vertebra cisim gerdirme, yaşam kalitesi.

\footnotetext{
Abstract

Objectives: Posterior instrumentation and fusion (PEF) is the standard surgical approach and vertebral body tethering (VBT) emerged as an alternative non-fusion technique in the treatment of idiopathic scoliosis. The aim of this study was to compare the correction and health-related life quality of the patients who have undergone PEF and VBT.

Materials and Methods: Matched cohorts were obtained among patients whose curves ranged between $40^{\circ}$ $70^{\circ}$ who had $>2$ years follow-up. Patients with a lumbar curve included in surgery were excluded. Patients' demographic data, perioperative and follow-up radiographic measurements, and SRS-22 scores were compared.

Results: 16 PEF and 18 VBT patients (30F, 4M) were included. The mean age and follow-up were 13.4 (10-17) years and 25.7 (24-32) months. Preoperative upper thoracic, main thoracic (MT), and thoracolumbar (TL) curves were similar among groups. The surgical correction percentage in the MT curve was greater in the PEF group $(84 \%-53 \%, p<0.001)$, while the overall correction percentage at two years was similar $(80-76 \%$, $\mathrm{p}=0.616)$. There was an improvement in self-image and subtotal scores at two years in PEF and VBT groups $(\mathrm{p}<0.001-\mathrm{p}=0.037$ and $\mathrm{p}<0.001-\mathrm{p}=0.016)$. In the PEF group, function scores at six months and two years $(\mathrm{p}=0.027)$, pain and sub-total scores at two years $(\mathrm{p}=0.020, \mathrm{p}=0.036)$ were found to be lower compared to VBT. Conclusion: Following PEF and VBT surgeries, a similar improvement was observed in MT and TL curves. While similar improvement is achieved in SRS22 scores, this improvement is dynamically progressed in VBT. Whether SRS22 scores are better in the VBT group should be examined in larger patient series with longer follow-up.

Keywords: Adolescent idiopathic scoliosis, posterior instrumentation and fusion, vertebral body tethering, quality of life.
} 


\section{Giriş}

Adölesan idiopatik skolyoz (AIS) sagital, aksiyel ve koronal düzlemde dizilim ve şekil değişiklikleri ile karakterize, omurganın 3 boyutlu deformitesidir. ${ }^{1}$ 10-18 yaş arasında görülen AIS'in tedavi seçenekleri hastanın eğriliğinin büyüklüğü, yerleşimi, kalan büyüme potansiyeli ve konservatif tedaviye cevabına göre değişiklik göstermektedir. ${ }^{2}$ Cerrahi torasik Cobb açısının $40^{\circ}$ üzerinde olduğu, iskelet olgunluğuna ulaşmamış veya eğriliği ilerlemeye devam eden hastalarda önerilmektedir. ${ }^{3}$ Deformitenin zaman içinde daha iyi anlaşılmasıyla geliştirilen çok segment, 3 kolon fiksasyon sağlayan pedikül vidalarının kullanımı kısa sürede yaygınlık kazanmıștır. Bu sayede skolyoz hastalarında yeterli düzeltme ve dengeli bir omurga dizilimi sağlandığı bildirilmiş ve posterior enstrümentasyon ve füzyon (PEF) tedavide standart yaklaşımı oluşturmuştur. ${ }^{4}$

Son yllarda füzyona alternatif olarak omurga biyomekaniğini koruyan füzyonsuz cerrahi yöntem, vertebra cisim gerdirme (VBT), giderek daha sık kullanılmaktadır. ${ }^{5}$ VBT, Hueter- Volkmann kanunu kullanarak ve kalan büyümeden faydalanarak, eğriliklerin kendiliğinden düzelmesini sağlayan bir büyüme yönlendirme yöntemidir.6,7 VBT ile mevcut deformiteyi tedavi ederken, daha fazla deformite oluşması engellenmekte ve hareket kısıtllılı̆̆ı minimumda tutularak estetik bir görünüm sağlanmaktır. Sadece skolyozun doğal seyrini değiştirilmediği, deformite düzeltmesinin de yapılabildiği bir yöntem olan VBT'de, farklı hasta serilerinde, aşırı düzelme, düzelmede kayıp, ipin kopması veya akciğer ile ilgili problemler gibi cerrahinin ve yöntemin sonuçları ve komplikasyonları hakkında bilgi verilmiştir. ${ }^{7-11}$

Adölesan idiopatik skolyozun farklı tedavi yöntemleri ile amaçlanan sadece anatomik düzeltme değil aynı zamanda hastaların iyilik hallerinin arttırılmasıdır. Skolyozlu hastalarda yaşam kalitesi ve sağlık sonuçlarının değerlendirilmesinde en sık kullanılan hastalığa özgü anket, skolyoz araştırma cemiyeti (Scoliosis Research Society) tarafından geliştirilmiş olan SRS-22 anketidir.12,13 Türkçe versiyonunun geçerliliği ve güvenirliliği de Alanay ve ark. tarafından gösterilmiştir. ${ }^{14}$ AIS hastalarında sağlıkla ilişkili yaşam kalitesi kavramının, gözlem ve korse gibi konservatif tedavilerle, posterior enstrümentasyon ve füzyon cerrahisi veya farklı cerrahi teknikler ile erken veya geç dönem ilişkileri çeşitli çalışmalarla gösterilmiştir. ${ }^{15-19}$ Ancak tedavide standart yaklaşım olan ve füzyon ile giderek popülerliği artan füzyonsuz vertebra cisim gerdirme yöntemlerini benzer cerrahi yaklaşım uygulanmış hasta gruplarında karşılaştırarak hastalar tarafından nasıl algılandığını ortaya koyan çalışma bulunmamaktadır.

$\mathrm{Bu}$ çalışma ile amaçlanan adölesan idiopatik skolyoz nedeniyle posterior enstrümentasyon ve füzyon ve vertebra cisim gerdirme yöntemleri ile ameliyat edilmiş, preoperatif benzer deformitelere sahip hasta kohortlarının, postoperatif düzelmeleri ve sağlıkla ilişkili yaşam kalitelerinin değerlendirilerek karşılaştııılmasıdır. 


\section{Materyal ve Metot}

Etik kurul onayının alınmasını takiben 2014-2019 tarihleri arasında tek merkezde VBT ve PEF cerrahileri uygulanmış prospektif olarak takip edilen adölesan idiopatik skolyoz hastaları retrospektif olarak incelendi. Hastaların demografik verileri, preoperatif, erken postoperatif ve takip radyografik ölçümleri ve hasta tarafından bildirilen sonuç anketleri "SRS-22 skorları", sağlıkla ilgili yaşam kalitesini değerlendirmek için kullanıldı.

İki farklı cerrahi grubunda eşleşen kohortlar elde edilebilmesi amacıyla en az takip süresi 2 yll olan preoperatif deformite büyüklüğü ve deformite tipi benzer hasta kohortları seçildi.

İki grupta, ana torasik eğrilik hakimiyetinde Lenke tip 1 ve 2 deformitesi olan hastalarda cerrahi sinır olan 40 derece üzeri eğriliği olanlar ${ }^{3}$ ve VBT için üst ameliyat sınırı olan 70 derece altında eğriliği olan ${ }^{7}$ hastalar çalışmaya dahil edildi. PEF'de eşlik eden posterior kolon osteotomisi yapılmış olan, Tip C veya Ar tipi lomber değiştiricisi olan hastalarda alttaki lomber eğriliğin cerrahiye dahil edildiği veya enstrümantasyonun 1. lomber vertebra distaline uzamış olduğu hastalar ve preoperatif ve takip SRS-22 anketleri eksik olan hastalar ile SRS22 anketi ile aynı takip tarihinde radyografisi olmayan hastalar çalışmadan çıkartıldı.

\section{Cerrahi teknik}

Bütün cerrahi prosedürler bir kıdemli cerrah tarafından uygulandı. Posterior enstrümentasyon ve füzyon cerrahisi, yüzüstü pozisyonda standart posterior orta hat yaklaşım ile gerçekleştirildi. İnferior fasetektomiler yapıldıktan sonra torasik pedikül vidaları yerleștirildi. Rodlar yerleştirildikten sonra translasyon, derotasyon, kantilever ve segmental kompresyon-distraksiyon manevralar ile deformite düzeltildi ve dekortikasyonu takiben graft yerleştirilerek işleme son verildi. Hastaların rutin preoperatif aktivitelerine 6 ay sonra dönmelerine izin verildi (Resim 1). Vertebra cisim gerdirme yöntemi lateral dekübit pozisyonunda, videoyardımlı torakoskopi yöntemi ile 3 görüntüleme, 3-4 işlem portu açılarak gerçekleştirildi. Mono-aksiyel vidalar birkortikal olacak șekilde konveks tarafta vertebra cisimlerine yerleștirildikten sonra translasyon ve derotasyon manevraları altında ip gerdirilerek sabitlendi. Preoperatif planlanan düzeltme, deformitenin miktarı ve kalan büyüme potansiyeline göre hesaplandı ve gerdirme miktarına işlem esnasında disk açllarındaki değişime göre karar verildi. İşlem bir adet göğüs tüpü yerleştirilerek tamamlandı. Hastaların rutin preoperatif aktivitelerine 6 hafta sonra dönmelerine izin verildi (Resim 2). 


\section{Hasta verileri}

Perioperatif veriler; cerrahi yöntem, cerrahi süre, tahmini cerrahi kanama miktarı, üst-alt enstrümante edilmiş vertebralar ve enstrümante edilen vertebra sayısını içeriyordu. Hastaların kemik olgunluğunun belirteci olarak preoperatif ve son takip olarak 2. yıl Risser işaretleri değerlendirildi. ${ }^{20}$ Hastaların cerrahi öncesi (preoperatif), erken postoperatif (6. hafta) ve son takip (2. yll) ön-arka ve yan skolyoz grafileri incelendi. Radyografik olarak hastaların üst, ana torasik (UT ve MT) ve torakolomber/lomber(TL/L) skolyoz açıları ile torasik kifoz (TK) ve lomber lordoz (LL) açıları Cobb yöntemi ile doğrulanmış bir yazılım kullanılarak (Centricity Enterprise-W version 3.0.10; General Electric, Milwaukee, WI, USA) ölçüldü. Koronal ölçümlerde aşırı düzelme durumu açısal olarak negatif işareti ile belirtildi. Ana torasik eğrilikteki cerrahi düzelme ((preoperatif -6. hafta) / preoperatif), takip düzelme ((6. hafta- 2. yll) / 6. hafta) ve toplam düzelme ((preoperatif - 2.yll) / preoperatif) oranları hesaplandı. Preoperatif, erken postoperatif (6. ay) ve takip dönemi (2. yıl) SRS-22 skorları çalışmaya dahil edildi. Skorlar; ağrı, kendi imaj/görüşü, fonksiyon/aktivite, ruh sağlı̆̆l, tatmin ve ara-toplam olmak üzere 6 alt başlıkta incelendi. Her alt başlıkta erken dönem ve son takip değişim miktarları hesaplandı. İstatistiksel analizlerde demografik ve perioperatif klinik ve radyolojik veriler iki cerrahi grubu arasında karşılaştırıldı. İstatistiksel analizler SPSS v. 23 (IBM, Armonk, NY, ABD) kullanılarak yapıldı. Sürekli değişskenler ANOVA, Mann-Whitney U testi ve kategorik değişkenler Ki-kare testi ile karşılaştırıldı. İstatiksel olarak anlamlılık $\mathrm{p}<0.05$ değerlerinde kabul edildi.

\section{Bulgular}

Eşleşmiş kohort kriterlerini karşılayan 16 PEF ve 18 VBT hastası çalışmaya dahil edildi. Çalışma grubu 30 kadın, 4 erkekten oluşmakta ve kohortun ortalama yaşı 13,4 yıl (10-17) idi. Ortalama takip süresi 25,7 (24-32) aydı. 34 hastanın 32'sinde Lenke tip 1, 2 hastada Lenke tip 2 eğrilik bulunmaktaydı. Hastaların lomber değiştiricileri 15 hastada A tipi, 14 hastada B tipi, 2 hastada C tipi, 3 hastada Ar tipi idi. Hiçbir hastada preoperatif nörolojik defisit yoktu.

İki grubun demografik, radyolojik ve cerrahi özellikleri Tablo 1'de yer almaktadır. PEF ve VBT gruplarında preoperatif UT $\left(28,6^{0}-29,6^{0}\right)$, MT $\left(56,8^{0}-51^{0}\right)$ ve TL/L $\left(32,5^{0}-37^{0}\right)$ skolyoz açları benzerdi (sırasıyla; $p=0,732$, $\mathrm{p}=0,126, \mathrm{p}=0,088)$. PEF grubunda 6 . haftada ana torasik eğrilikte cerrahi düzelmenin VBT grubuna göre daha fazla olduğu (\%84-\%53, p<0.001) ve 6. hafta MT skolyoz açısının daha az olduğu görüldü $\left(8,8^{0}-23,9^{0}, p<0,001\right)$. PEF ve VBT gruplarında 2. yılda ise toplam düzelme oranları (\%80-\%76) ve ana torasik skolyoz açıları $\left(11,2^{0}-\right.$ $12,1^{0}$ ) benzerdi (sırasıyla; $\mathrm{p}=0,616, \mathrm{p}=0,838$ ). PEF grubunun UT skolyoz açıları, 6. haftada ve 2.ylda VBT grubundan istatiksel olarak anlamlı şekilde düşüktü $\left(9,8^{0}\right.$ ve $11,2^{0}-20,6^{0}$ ve $\left.15,8^{0}, p<0,001, p=0,030\right)$. UT eğriliğin cerrahi düzelme / toplam düzelme oranları, PEF grubunda (\%65-\%62) VBT grubuna göre (\%29\%46) istatiksel olarak daha yüksekti $(p<0,001 / p=0,040)$. TL/L eğriliğin cerrahi düzelmesi PEF grubunda 
(\%65) VBT grubuna göre (\%47) istatiksel olarak anlamlı olarak daha yüksek görüldü (p 0,010). Toplam düzelme oranları iki grup arasında benzer saptandı (\%68-\%80, p=0,422). İki grup arasında, preoperatif, 6 . hafta ve 2. yıl radyografilerinde torakolomber eğriliklerindeki skolyoz, torakal kifoz ve lomber lordoz açılarında anlamlı fark saptanmadı.

Tablo 1. Posterior enstrümentasyon ve füzyon (PEF) ile vertebra cisim gerdirme (VBT) ameliyat kohortlarının demografik, radyolojik, cerrahi karakteristikleri ve karşılaştırmaları

\begin{tabular}{|c|c|c|c|}
\hline Değişkenler & PEF & VBT & $\mathbf{P}$ \\
\hline & $n=16$ & $n=18$ & \\
\hline Yaș (yıl) & $14,4(12-17)$ & $12,6(10-15)$ & 0,001 \\
\hline Cinsiyet (K/E) & $13 / 3$ & $17 / 1$ & 0,698 \\
\hline Preoperatif Risser & $3,4(1-5)$ & $1,3(0-4)$ & 0,001 \\
\hline 2. yll Risser & $4,2(3-5)$ & $3,4(0-5)$ & 0,036 \\
\hline Enstrümante Seviye Sayısı & $9,3(8-12)$ & $7,5(7-9)$ & 0,001 \\
\hline Cerrahi Süresi (dakika) & $350(210-500)$ & $239(123-360)$ & 0,001 \\
\hline Kanama Miktarı (ml) & $234(50-450)$ & $79(40-150)$ & 0,001 \\
\hline \multicolumn{4}{|l|}{ Skolyoz Açıları } \\
\hline \multicolumn{4}{|l|}{ Üst Torasik Eğrilik } \\
\hline $\begin{array}{l}\text { Preoperatif }\left({ }^{\circ}\right) \\
\text { 6.hafta Postoperatif }\left(\left(^{\circ}\right)\right. \\
\text { 2.yll Postoperatif }\left({ }^{\circ}\right)\end{array}$ & $\begin{array}{l}28,6(14-47) \\
9,8(3-20) \\
11,1(3-28)\end{array}$ & $\begin{array}{l}29,6(17-44) \\
20,6(8-34) \\
15,8(4-36)\end{array}$ & $\begin{array}{l}0,732 \\
\mathbf{0 , 0 0 1} \\
\mathbf{0 , 0 3 0}\end{array}$ \\
\hline \multicolumn{4}{|l|}{ Ana Torasik Eğrilik } \\
\hline $\begin{array}{l}\text { Preoperatif }\left({ }^{\circ}\right) \\
\text { 6.hafta Postoperatif }\left({ }^{\circ}\right) \\
\text { Cerrahi Düzelme }(\%) \\
\text { 2.yll Postoperatif }\left(^{\circ}\right) \\
\text { Toplam Düzelme }(\%)\end{array}$ & $\begin{array}{l}56,8(43-72) \\
8,8(1-19) \\
84(71-98) \\
11,2(1-23) \\
80(69-98)\end{array}$ & $\begin{array}{c}51(43-68) \\
23,9(14-33) \\
53(40-71) \\
12,1(-16-28) \\
76(44-129)\end{array}$ & $\begin{array}{l}0,126 \\
\mathbf{0 , 0 0 1} \\
\mathbf{0 , 0 0 1} \\
0,838 \\
0,616\end{array}$ \\
\hline \multicolumn{4}{|l|}{ Torakolomber Eğrilik } \\
\hline $\begin{array}{l}\text { Preoperatif }\left({ }^{\circ}\right) \\
\text { 6.hafta Postoperatif }\left({ }^{\circ}\right) \\
\text { 2.yll Postoperatif }\left({ }^{\circ}\right)\end{array}$ & $\begin{array}{c}32,5(22-43) \\
13(1-28) \\
11,6(1-22)\end{array}$ & $\begin{array}{l}37(29-52) \\
17,4(3-28) \\
6,9(-4-31)\end{array}$ & $\begin{array}{l}0,088 \\
0,135 \\
0,198\end{array}$ \\
\hline \multicolumn{4}{|l|}{ Torakal Kifoz $\left({ }^{\circ}\right)$} \\
\hline $\begin{array}{l}\text { Preoperatif } \\
\text { 6.hafta Postoperatif } \\
\text { 2.yll Postoperatif }\end{array}$ & $\begin{array}{c}32 \pm 11,1 \\
27,1 \pm 9 \\
31,4 \pm 10,8\end{array}$ & $\begin{array}{c}30,2 \pm 7,9 \\
27,5 \pm 8,2 \\
28,1 \pm 7\end{array}$ & $\begin{array}{l}0,592 \\
0,884 \\
0,283 \\
\end{array}$ \\
\hline \multicolumn{4}{|l|}{ LomberLordoz $\left({ }^{\circ}\right)$} \\
\hline $\begin{array}{l}\text { Preoperatif } \\
\text { 6.hafta Postoperatif } \\
\text { 2.yll Postoperatif }\end{array}$ & $\begin{array}{c}61,6 \pm 7,8 \\
51,1 \pm 11,5 \\
57,3 \pm 9,5\end{array}$ & $\begin{array}{c}64,1 \pm 11,1 \\
55,1 \pm 17,9 \\
56,1 \pm 7,3\end{array}$ & $\begin{array}{l}0,347 \\
0,454 \\
0,659\end{array}$ \\
\hline
\end{tabular}

n: Hasta sayısı; K: Kadın; E: Erkek; ml: Mililitre; ${ }^{\circ}$ Açı; \%: Yüzde 
Tablo 2. Posterior enstrümentasyon ve füzyon (PEF) ile vertebra cisim gerdirme (VBT) ameliyat kohortlarının SRS22 anketlerinin preoperatif, postoperatif 6. ay ve 2. yıl sonuçları ve karşılaştırmaları

\begin{tabular}{|c|c|c|c|}
\hline \multirow{2}{*}{ SRS22 skorları } & PEF & VBT & \multirow{2}{*}{$\mathbf{p}$} \\
\hline & $\mathrm{n}=16$ & $\mathrm{n}=18$ & \\
\hline \multicolumn{4}{|l|}{ Ağrı } \\
\hline Preoperatif & $3,85 \pm 0,76$ & $4,18 \pm 0,67$ & 0,179 \\
\hline 6. ay Postoperatif & $4,2 \pm 0,82$ & $4,62 \pm 0,39$ & 0,107 \\
\hline 2. yll Postoperatif & $4,3 \pm 0,47$ & $4,57 \pm 0,62$ & 0,020 \\
\hline \multicolumn{4}{|l|}{ Kendi İmajı/ Görüșü } \\
\hline Preoperatif & $3,13 \pm 0,61$ & $3,38 \pm 0,65$ & 0,259 \\
\hline 6. ay Postoperatif & $4,15 \pm 0,39$ & $3,92 \pm 0,84$ & 0,410 \\
\hline 2. yll Postoperatif & $4,14 \pm 0,56$ & $4,24 \pm 0,61$ & 0,615 \\
\hline \multicolumn{4}{|l|}{ Fonksiyon/Aktivite } \\
\hline Preoperatif & $4,33 \pm 0,73$ & $4,53 \pm 0,69$ & 0,347 \\
\hline 6. ay Postoperatif & $3,96 \pm 0,68$ & $4,51 \pm 0,57$ & 0,027 \\
\hline 2. yll Postoperatif & $4,28 \pm 0,55$ & $4,66 \pm 0,40$ & 0,027 \\
\hline \multicolumn{4}{|l|}{ Ruh Sağlığı } \\
\hline Preoperatif & $3,43 \pm 0,50$ & $3,61 \pm 0,51$ & 0,326 \\
\hline 6. ay Postoperatif & $3,55 \pm 0,57$ & $3,54 \pm 0,55$ & 0,983 \\
\hline 2. yll Postoperatif & $3,43 \pm 0,68$ & $3,87 \pm 0,77$ & 0,091 \\
\hline \multicolumn{4}{|l|}{ Tatmin } \\
\hline 6. ay Postoperatif & $4,54 \pm 0,54$ & $4,58 \pm 0,69$ & 0,616 \\
\hline 2. yll Postoperatif & $4,34 \pm 0,94$ & $4,8 \pm 0,34$ & 0,154 \\
\hline \multicolumn{4}{|l|}{ Ara-toplam } \\
\hline Preoperatif & $3,68 \pm 0,47$ & $3,93 \pm 0,49$ & 0,153 \\
\hline 6. ay Postoperatif & $3,96 \pm 0,37$ & $4,15 \pm 0,49$ & 0,291 \\
\hline 2. yll Postoperatif & $4,04 \pm 0,43$ & $4,35 \pm 0,49$ & 0,036 \\
\hline
\end{tabular}

n: Hasta sayısı

PEF ve VBT gruplarında SRS22 skorlarının preoperatif, 6. ay ve 2. yıldaki ağrı, kendi imaj/görüşü, fonksiyon/aktivite, ruh sağlığı, tatmin ve ara toplam skorları ve karşılaștırmaları Tablo 2'de yer almaktadır. Preoperatif dönemde gruplar arasında ağrı, kendi imaj/görüşü, fonksiyon/aktivite, ruh sağlığı ve ara toplam skorlarında fark bulunmadı. PEF grubunda, fonksiyon/ aktivite alt başlığındaki skorların 6. ayda VBT grubundan anlamlı olarak düșük olduğu görüldü $(3,96 \pm 0,68-4,51 \pm 0,57, p=0,027)$. Ağrı, fonksiyon/aktivite, ara-toplam alt başlıklarındaki skorların 2.yılda PEF grubunda istatiksel olarak anlamlı düşük olduğu saptandı ( p 0,020, p 0,027, p 0,036). 6.aydaki ve 2.yıldaki diğer SRS22 skorlarının benzer olduğu belirlendi.

SRS22 skorlarının preoperatif dönemden postoperatif 6. ay ve 2.yıldaki değişimlerinin PEF ve VBT gruplarındaki ayrı ayrı karşılaştırmaları Tablo 3'te gösterilmektedir. Preoperatif döneme kıyasla 6. ayda PEF grubunda kendi imaj/görüşünde $(\mathrm{p}<0,001)$, VBT grubunda ağrı ve kendi imaj/görüşünde iyileşme olduğu belirlendi (sırasıyla; p=0,028, p=0,044). Preoperatif döneme göre 2. yılda PEF ve VBT gruplarında kendi imaj/görüşünde ve ara toplamda istatiksel olarak anlamlı iyileşme olduğu saptandı (sırasıyla; $p<0,001$, $p=0,037$ ve $p<0,001, p=0,016)$. 
Genel kohortta cerrahi süre ve kanama miktarı ile 6. ay ağrı skoru arasında orta-güçlü negatif korelasyon olduğu (r=-0,411, p=0,027 ve r=-0,687, p<0,001), 24. ay UT skolyoz açısı ile tatmin skoru arasında negatif zayıf korelasyon olduğu görüldü ( $\mathrm{r}=-0,346, \mathrm{p}=0,045)$. Takip ve toplam düzelme oranları ile SRS22 alt başlıklarındaki skorlar arasındaki ilişkiye bakıldığında; üst torasik, ana torasik ve torakolomber eğriliklerdeki takip düzelme miktarı ile 2. yıldaki tatmin skorları arasında orta-güçlü korelasyon olduğu görüldü $(r=0,572, r=0,712, r=0,733$, $\mathrm{p}<0,001)$.

Tablo 3. Posterior enstrümentasyon ve füzyon (PEF) ile vertebra cisim gerdirme (VBT) ameliyat kohortlarında, preoperatif, postoperatif 6. ay ve postoperatif 24. Ayda Ağrı, Kendi İmajı/Görüşü, Fonksiyon/Aktivite, Ruh Sağlı̆̆ı, Tatmin ve Ara-Toplam skorlarındaki değişimler ve karşılaştırmaları

\begin{tabular}{|c|c|c|c|c|c|c|}
\hline & Preoperatif & 6.Ay & Pre-6 & 24.Ay & $6-24$ & Pre-24 \\
\hline SRS22 skorları & & & P değeri & & P değeri & P değeri \\
\hline \multicolumn{7}{|l|}{ PEF } \\
\hline $\begin{array}{l}\text { Ağrı } \\
\text { Kendi İmaj/ Görüșü } \\
\text { Fonksiyon/Aktivite } \\
\text { Ruh Sağlığı } \\
\text { Tatmin } \\
\text { Ara-Toplam }\end{array}$ & $\begin{array}{c}3,85 \pm 0,76 \\
3,13 \pm 0,61 \\
4,33 \pm 0,73 \\
3,43 \pm 0,50 \\
- \\
3,68 \pm 0,47\end{array}$ & $\begin{array}{c}4,2 \pm 0,82 \\
4,15 \pm 0,39 \\
3,96 \pm 0,68 \\
3,55 \pm 0,57 \\
4,54 \pm 0,54 \\
3,96 \pm 0,37\end{array}$ & $\begin{array}{c}0,135 \\
<\mathbf{0 , 0 0 1} \\
0,185 \\
0,587 \\
- \\
0,103\end{array}$ & $\begin{array}{c}4,3 \pm 0,47 \\
4,14 \pm 0,56 \\
4,28 \pm 0,55 \\
3,43 \pm 0,68 \\
4,34 \pm 0,94 \\
4,04 \pm 0,43\end{array}$ & $\begin{array}{l}0,711 \\
0,961 \\
0,196 \\
0,651 \\
0,522 \\
0,652\end{array}$ & $\begin{array}{c}0,054 \\
<\mathbf{0 , 0 0 1} \\
0,829 \\
0,950 \\
- \\
\mathbf{0 , 0 3 7}\end{array}$ \\
\hline \multicolumn{7}{|l|}{ VBT } \\
\hline $\begin{array}{l}\text { Ağrı } \\
\text { Kendi İmaj/ Görüşü } \\
\text { Fonksiyon/Aktivite } \\
\text { Ruh Sağlığı } \\
\text { Tatmin } \\
\text { Ara-Toplam }\end{array}$ & $\begin{aligned} 4,18 & \pm 0,67 \\
3,38 & \pm 0,65 \\
4,53 & \pm 0,69 \\
3,61 & \pm 0,51 \\
& - \\
3,93 & \pm 0,49\end{aligned}$ & $\begin{array}{l}4,62 \pm 0,39 \\
3,92 \pm 0,84 \\
4,51 \pm 0,57 \\
3,54 \pm 0,55 \\
4,58 \pm 0,69 \\
4,15 \pm 0,49\end{array}$ & $\begin{array}{c}\mathbf{0 , 0 2 8} \\
\mathbf{0 , 0 4 4} \\
0,943 \\
0,701 \\
- \\
0,194\end{array}$ & $\begin{array}{l}4,57 \pm 0,62 \\
4,24 \pm 0,61 \\
4,66 \pm 0,40 \\
3,87 \pm 0,77 \\
4,8 \pm 0,34 \\
4,35 \pm 0,49\end{array}$ & $\begin{array}{l}0,798 \\
0,222 \\
0,383 \\
0,152 \\
0,244 \\
0,249\end{array}$ & $\begin{array}{c}0,081 \\
<\mathbf{0 , 0 0 1} \\
0,489 \\
0,232 \\
- \\
\mathbf{0 , 0 1 6}\end{array}$ \\
\hline
\end{tabular}

(Pre-6; Preoperatif - postoperatif 6.ay skorlardaki değişimlerin P değeri, 6-24; Postoperatif 6. ay - 24.ay skorlardaki değişimlerin P değeri, Pre-24; Preoperatif- postoperatif 24. ay skorlardaki değișimlerin P değeri)

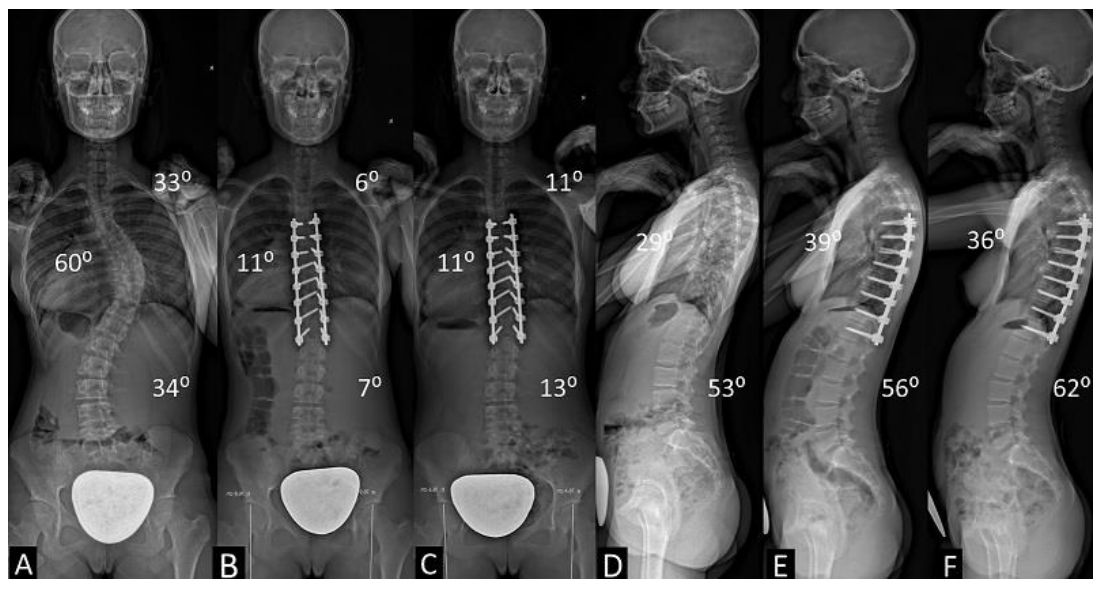

Resim 1. Posterior

enstrümentasyon ve füzyon uygulanmış adölesan idiopatik Skolyoz hastası.

(A-D: Preoperatif ön-arka ve yan grafi, B-E: 6. hafta ön-arka ve yan grafi, C-F: 2. yıl ön-arka ve yan grafi) 


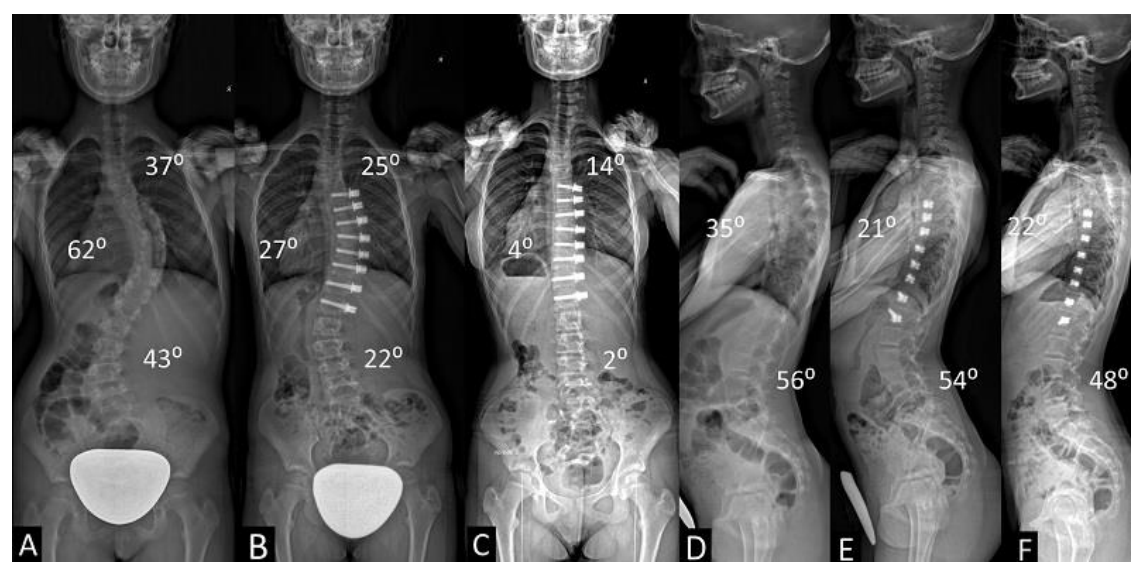

Resim 2: Vertebra cisim gerdirme uygulanmış adölesan idiopatik skolyoz hastası (A-D: Preoperatif ön-arka ve yan grafi, B-E: 6. hafta ön-arka ve yan grafi, C-F: 2. yll ön-arka ve yan grafi)

\section{Tartışma}

Mevcut çalışma, adölesan idiopatik skolyozda, selektif olarak torakal bölgeye uygulanmış posterior enstrümetasyon ve füzyon cerrahisi ve vertebra cisim gerdirme cerrahisinin erken dönem sonuçlarını ve sağlıkla ilişkili yaşam kalitesi üzerindeki etkilerini klinik olarak araştıran ilk çalışmadır. Torakal eğriliğin benzer olduğu kohortlarda, SRS22'nin idiopatik skolyozdaki sağlıkla ilişkili yaşam kalitesini anlama kabiliyetine dayanarak, preoperatif, erken postoperatif ve takip radyografik ve SRS22 skorlarının incelendiği çalışmada, 2. yılda ağrı, fonksiyon/aktivite ve ara-toplam skorlarının VBT grubunda daha iyi olduğu belirlendi. Cerrahi yapılan eğrilikteki değişim ile 2. yıldaki tatmin skorları arasında güçlü ilişki olduğu görüldü.

Adölesan idiopatik skolyozda tedavinin temelini periyodik gözlem, skolyoza özgü egzersizler ve korse uygulaması oluşturmaktadır. Ameliyat gerektiren daha az sayıdaki hastalar için, posterior enstrümentasyon ve füzyon standart tedavi yöntemi olmuștur ve hala öyledir. ${ }^{3}$ Uzun vadeli iyi sonuçlarla etkinliği kanıtlanmış olsa dahi uygulandığı segmentlerde büyüme ve hareket kalıcı olarak durdurulmakta ve bu da bitişik segmentlerde yük dağlımını değiştirmektedir. ${ }^{21}$ Ayrıca AIS, psikososyal işlev ve beden imajı dahil olmak üzere sağlıkla ilgili yaşam kalitesinde kötüleşmeye neden olur. ${ }^{22}$ Bu nedenle cerrahi tedavinin birincil hedeflerinden biri, zaman içinde yaşam kalitesinde bozulmasını azaltmaktır. Standart yaklaşım olan füzyon cerrahisi takibinde, normal popülasyona kıyasla, erken dönemde, SRS22 skorlarının benzer olduğu ama 10 yıl ve üzeri takiplerde SRS22 skorlarının düşme eğiliminde olduğu, özellikle diğer alt başlıklara kıyasla hastaların kendi imajı/görüşü’nde ciddi kötüleşme olduğu bildirilmektedir. ${ }^{23}$

Cerrahi tedavide alternatif olarak vertebra cisim gerdirme yöntemi, devam eden spinal ve gögüs kafesi büyümesine müsaade ederken, daha fizyolojik şekilde eğrilikte stabilizasyon ve fonksiyonel hareketin korunmasını sunan ilk umut verici füzyonsuz cerrahi teknik olarak ortaya çıkmıştır. ${ }^{7-11}$ Cerrahi düzeltmeyi takiben kalan büyüme potansiyeli kullanılarak takip düzeltmesi elde edilen VBT’de başarı, cerrahi düzeltme 
miktarının iyi belirlenmesi, kalan büyüme potansiyelinin iyi hesaplanması gibi faktörlere bağlıdır. ${ }^{7}$ VBT cerrahisi ile sağlıkla ilişkili yaşam kalite anketlerinin sonuçlarında iyileşme olduğu daha önce gösterilmiştir; Wong ve ark. 3 yıl takipte preoperatif döneme göre SRS22 skorlarında iyileşme olduğunu bildirirken, Pehlivanoglu ve ark. VBT cerrahisi takibinde, eşleşmiş PEF grubuna kıyasla istatiksel olarak anlamlı yüksek SRS22 skorları olduğunu belirtmektedirler. ${ }^{11,19}$ Ancak araştırılan iki kohorttaki cerrahi yaklaşımların homojen olmaması, sonuçları değerlendirmede zayıflık oluşturmaktadır. Çalışmamızda preoperatif döneme kıyasla 6. ayda ve 2. yılda kendi imaj/görüş skorlarında ve 2. yılda ara-toplam skorlarında anlamlı iyileșme olduğu iki kohort içerisinde de benzer şekilde görülmektedir. Ek olarak VBT grubunda 6. ayda ağrı skorunda belirgin anlamlı bir iyileşme saptanmıştır.

Doktorlar için eğriliğin progresyon göstererek oluşturacağı tıbbi sorunları çözmek birincil amaç iken hastalar için en önemli beklentinin estetik kaygıların ortadan kaldırılması ve hayat kalitesinin düzelmesi olduğu bilinmektedir.24 Füzyon cerrahisi sonrasında yaşam kalitesinde görülen azalmanın, cerrahi sonrasında fiziksel aktivitelere katılmadaki azalma ve sosyal aktivitelerdeki kısıtlanma nedeniyle olduğu gösterilmiştir. ${ }^{25}$ Lomber bölgede hareketli segmentlerin korunması ile eklem hareket açıklı̆̆ının korunduğu ve füzyonun L2 üzerinde sonlanması ile artmış hasta memnuniyeti bildirilmiştir. ${ }^{26}$ Selektif torasik füzyonun, hastaların günlük aktivitelerini gerçekleştirme yeteneklerini geliştirerek yaşam kalitesini olumlu yönde etkileyebileceği ve eğriliklerdeki iyileşmenin yanı sıra, yaşam kalitelerinin yıllar sonra normal popülasyona benzer olduğu gösterilmiştir. ${ }^{27,28}$ Ohashi ve ark. tarafından selektif torasik füzyona rağmen global spinal hareket açıklı̆̆ında önemli bir azalma bildirilmiştir ama Hamzaoglu ve ark. selektif füzyon yapılan hastalarda 15 yıl takipte sağlıkla ilgili yaşam kalitesi sonuçlarının, yaş-cinsiyet-vücut kitle indeksi eşleşmiş kontrol grubu ile benzer olduğunu bildirmişlerdir. ${ }^{15,29} \mathrm{Bu}$ sebeple mevcut çalışmada sadece torakal bölge cerrahisi uygulanmış ana torasik eğriliği olan AIS hastaları değerlendirilerek, cerrahinin yarattığı fonksiyon kısıtlılığından bağımsız, uygulanan cerrahi yöntemin yaşam kalitesi üzerindeki erken ve geç dönem etkisi de incelenmiştir.

Çalışmada hem posterior enstrümentasyon ve füzyon hem de vertebra cisim gerdirme cerrahileri sonrasında hastaların kendi imaj/görüşleri ve ara-toplam skorlarında benzer şekilde iyileşme olduğu görüldü. Preoperatif istatiksel olarak benzer SRS22 skorları olan gruplarda, PEF cerrahisi takibinde hastaların daha uzun cerrahi süre ve kanama miktarına sahip olmalarına rağmen 6. ay SRS22 skorları, fonksiyon/aktivite haricinde VBT grubuna benzer olduğu ama VBT grubunda fonksiyon/aktivite skorlarının hem erken dönem hem de takipte PEF grubundan anlamlı olarak daha iyi olduğu saptandı. İstatiksel olarak anlamlı olmamakla beraber cerrahi düzelme miktarının \%84 olduğu PEF grubunda 6. ay kendi imajı/görüşünün, cerrahi düzelmenin \%53 olduğu VBT grubuna göre daha iyi olduğu ancak takipte iki grupta benzer toplam düzelme gerçekleștikten sonra (\%80-\%76), 2. yılda kendi imajı/görüşü skorlarının benzer (VBT grubunda daha iyi) olduğu belirlendi. Aynı zamanda kanama miktarı-cerrahi süre arttıkça 6. ay ağrı skorlarında kötüleşme olduğu görüldü. 
PEF grubundan farklı olarak iyileşmenin dinamik olarak devam ettiği VBT'de radyografik ve klinik sonuçlar kadar yaşam kalite anket sonuçları da süreçten dinamik olarak etkilenmektedir. Dinamik süreç, kendi imaj/ görüşü gibi SRS22 skorlarındaki değişimin, cerrahi düzelme miktarı az ama takip düzelme miktarı fazla olan VBT grubundaki giderek iyileşen skorlarından anlaşılabilir. Bu nedenle büyüme yönlendirme yöntemi olan VBT'de yaşam kalitesinin anlaşılabilmesi için büyüme modülasyonu süreci boyunca, daha uzun dönem takip gerekmektedir.

Çalışmamızda bazı kısıtlılıklar bulunmaktadır. Eğriliğin boyutu ve tipleri üzerinden benzer hasta grupları ve eşleşmiş kohortlar elde edilmiş olsa da hasta kohortları arasında, PEF grubunun VBT grubuna kıyasla hem kronolojik hem de iskelet olgunluk belirteçleri açısından daha matür olması ciddi kısıtlılık yaratmaktadır. Bu durum, endikasyonlar nedeniyle füzyonun teknik olarak iskelet matüritesinin ilerisinde olan çocuklarda gerçekleştirilirken, VBT'nin daha immatür çocuklarda büyüme yönlendirme amacıyla uygulanması nedeniyle görülmektedir. Ancak VBT'nin uygulandığl, erken yaş döneminde, PEF cerrahisinin uygulanmasının komplikasyon riskini arttırdığı, bu nedenle uygulanmadığı ve korse gibi geciktirme taktikleri uygulandığı göz önüne alındığında, iki cerrahi grup için benzer yaş dağılımına sahip kohortlar elde etmenin oldukça zor olduğu bilinmektedir. ${ }^{30}$ Diğer bir kısıtlılık ise iki grup içerisindeki hastaların takip protokolleri, skolyoz spesifik egzersiz- korse gibi postoperatif destekleyici tedavilerinin yaşam kalitesi üzerine etkilerinin bilinmiyor olmasıdır. Bu konuda daha geniş hasta kohortlarında, preoperatif ve postoperatif takip protokolleri eşleşmiş çalışma kohortlarında ileri araştırmaya ihtiyaç bulunmaktadır.

Sonuç olarak eğriliğin benzer olduğu adölesan idiopatik skolyoz hastalarında 2. yılda hem ameliyat edilen torakal hem de ameliyat edilmeyen lomber eğriliklerde, posterior enstrümentasyon ve füzyon ile vertebra cisim gerdirme cerrahisinde benzer oranda düzelme görülmektedir. Sağlıkla ilgili yaşam kalitesinde, iki cerrahi yöntem ile, 2. yılda benzer şekilde düzelme elde edilirken, VBT de bu süreç dinamik olarak seyretmektedir. İki grup arasında fonksiyon/aktivite alt skorları VBT grubunda hem erken dönem hem takipte füzyona klyasla daha iyi olmakla beraber, bu konuda daha geniş hasta kohortlarında, daha uzun takip serilerinde çalışma yapılması gerekmektedir.

\section{Etik onay}

Bu çalışma için Acıbadem üniversitesi tıp fakültesi tıbbi araştırmalar değerlendirme kurulu 29.07.2021 tarihli 2021/14 sayılı 2021-14/46 karar numaralı etik onayı alınmıştır.

\section{Çıkar Çatışması}

Yazarlar herhangi bir çıkar çatışması olmadı̆̆ını beyan ve taahhüt ederler. 


\section{Kaynaklar}

1. Hattori T, Sakaura H, Iwasaki M, Nagamoto Y, Yoshikawa H, Sugamoto K. In vivo three-dimensional segmental analysis of adolescent idiopathic scoliosis. Eur Spine J. 2011;20(10):1745-50. (doi:10.1007/s00586-011-1869-4).

2. Addai D, Zarkos J, Bowey AJ. Current concepts in the diagnosis and management of adolescent idiopathic scoliosis. Childs Nerv Syst. 2020;36(6):1111-9. (doi:10.1007/s00381-020-04608-4).

3. Wagner SC, Lehman RA, Lenke LG. Surgical management of adolescent idiopathic scoliosis. Seminars in Spine Surgery. 2015;27(1):33-8. (doi: 10.1053/j.semss.2015.01.008).

4. Suk SI, Lee CK, Kim WJ, Chung YJ, Park YB. Segmental pedicle screw fixation in the treatment of thoracic idiopathic scoliosis. Spine (Phila Pa 1976). 1995;20(12):1399-405.

5. Driscoll M, Aubin CE, Moreau A, Parent S. Biomechanical comparison of fusionless growth modulation corrective techniques in pediatric scoliosis. Med Biol Eng Comput. 2011;49(12):1437-45. (doi:10.1007/s11517-011-0801-8).

6. Mehlman CT, Araghi A, Roy DR. Hyphenated history: the Hueter-Volkmann law. Am J Orthop (Belle Mead NJ). 1997;26(11):798-800.

7. Alanay A, Yucekul A, Abul K, et all. Thoracoscopic Vertebral Body Tethering for Adolescent Idiopathic Scoliosis: Follow-up Curve Behavior According to Sanders Skeletal Maturity Staging. Spine (Phila Pa 1976). 2020;45(22):E1483-E92. (doi:10.1097/BRS.0000000000003643).

8. Samdani AF, Ames RJ, Kimball JS, et all. Anterior vertebral body tethering for idiopathic scoliosis: twoyear results. Spine (Phila Pa 1976). 2014;39(20):1688-93. (doi:10.1097/BRS.0000000000000472).

9. Samdani AF, Ames RJ, Kimball JS, et all. Anterior vertebral body tethering for immature adolescent idiopathic scoliosis: one-year results on the first 32 patients. Eur Spine J. 2015;24(7):1533-9. (doi:10.1007/s00586-014-3706-z).

10. Newton PO, Kluck DG, Saito W, Yaszay B, Bartley CE, Bastrom TP. Anterior Spinal Growth Tethering for Skeletally Immature Patients with Scoliosis: A Retrospective Look Two to Four Years Postoperatively. J Bone Joint Surg Am. 2018;100(19):1691-7. (doi:10.2106/JBJS.18.00287).

11. Wong HK, Ruiz JNM, Newton PO, Gabriel Liu KP. Non-Fusion Surgical Correction of Thoracic Idiopathic Scoliosis Using a Novel, Braided Vertebral Body Tethering Device: Minimum Follow-up of 4 Years. JB JS Open Access. 2019;4(4):e0026. (doi:10.2106/JBJS.0A.19.00026).

12. Asher M, Min Lai S, Burton D, Manna B. The reliability and concurrent validity of the scoliosis research society-22 patient questionnaire for idiopathic scoliosis. Spine (Phila Pa 1976). 2003;28(1):63-9. (doi:10.1097/00007632-200301010-00015). 
13. Parent EC, Hill D, Mahood J, Moreau M, Raso J, Lou E. Discriminative and predictive validity of the scoliosis research society-22 questionnaire in management and curve-severity subgroups of adolescents with idiopathic scoliosis. Spine (Phila Pa 1976). 2009;34(22):2450-7. (doi:10.1097/BRS.0b013e3181af28bf).

14. Alanay A, Cil A, Berk H, et all. Reliability and validity of adapted Turkish Version of Scoliosis Research Society-22 (SRS-22) questionnaire. Spine (Phila Pa 1976). 2005;30(21):2464-8. (doi:10.1097/01.brs.0000184366.71761.84).

15. Hamzaoglu A, Karadereler S, Kahraman S, et all. Clinical, radiological and HRQoL outcomes after selective thoracic fusion with minimum 15-year follow-up. Spine Deform. 2021;9:1323-31. (doi:10.1007/s43390021-00350-2).

16. Chau WA-O, Ng BA-O, Hung AA-O. Health-related quality of life (HRQOL) of adolescent idiopathic scoliosis (AIS) patients from surgery to after 30 years using SRS-22 questionnaire. Spine Deform. 2020;8(5):951-6.

17. Watanabe K, Ohashi M, Hirano T, et all. Health-Related Quality of Life in Nonoperated Patients With Adolescent Idiopathic Scoliosis in the Middle Years: A Mean 25-Year Follow-up Study. Spine (Phila Pa 1976). 2020;45(2):E83-E9. (doi:10.1097/BRS.0000000000003216).

18. Senkoylu A, Taşkesen A, Ataoğlu M, Özer M, Altun N. There Is No Difference Between Hybrid And Pedicle Screw Techniques Regarding The SRS-22 Questionnaire. The Journal of Turkish Spinal Surgery. 2009;2009:31-8.

19. Pehlivanoglu T, Oltulu I, Erdag Y, et all. Comparison of clinical and functional outcomes of vertebral body tethering to posterior spinal fusion in patients with adolescent idiopathic scoliosis and evaluation of quality of life: preliminary results. Spine Deform. 2021;9:1175-82. (doi:10.1007/s43390-021-00323-5).

20. Risser JC. The Iliac apophysis; an invaluable sign in the management of scoliosis. Clinical Orthopaedics and Related Research. 1958;11:111-9.

21. Green DW, Lawhorne TW, 3rd, Widmann RF, et all. Long-term magnetic resonance imaging follow-up demonstrates minimal transitional level lumbar disc degeneration after posterior spine fusion for adolescent idiopathic scoliosis. Spine (Phila Pa 1976). 2011;36(23):1948-54. (doi:10.1097/BRS.0b013e3181ff1ea9).

22. Tones M, Moss N, Polly DW, Jr. A review of quality of life and psychosocial issues in scoliosis. Spine (Phila Pa 1976). 2006;31(26):3027-38. (doi:10.1097/01.brs.0000249555.87601.fc).

23. Chau WW, Ng BK, Hung AL. Health-related quality of life (HRQOL) of adolescent idiopathic scoliosis (AIS) patients from surgery to after 30 years using SRS-22 questionnaire. Spine Deform. 2020;8(5):951-6. (doi:10.1007/s43390-020-00132-2).

24. Negrini S, Grivas TB, Kotwicki T, et all. Why do we treat adolescent idiopathic scoliosis? What we want to obtain and to avoid for our patients. SOSORT 2005 Consensus paper. Scoliosis. 2006;1(1):4. (doi:10.1186/1748-7161-1-4). 
25. Danielsson AJ, Romberg K, Nachemson AL. Spinal range of motion, muscle endurance, and back pain and function at least 20 years after fusion or brace treatment for adolescent idiopathic scoliosis: a casecontrol study. Spine (Phila Pa 1976). 2006;31(3):275-83. (doi:10.1097/01.brs.0000197652.52890.71).

26. Etemadifar MR, Andalib A, Mahdinezhad Yazdi M, Farzinnia S. Evaluation of long term outcome of selective fusion in patients with idiopathic scoliosis. Int J Burns Trauma. 2021;11(1):48-53.

27. Matsumoto H, Colacchio ND, Schwab FJ, Lafage V, Roye DP, Vitale MG. Flatback Revisited: Reciprocal Loss of Lumbar Lordosis Following Selective Thoracic Fusion in the Setting of Adolescent Idiopathic Scoliosis. Spine Deform. 2015;3(4):345-51. (doi:10.1016/j.jspd.2015.01.004).

28. Enercan M, Kahraman S, Cobanoglu M, et all. Selective Thoracic Fusion Provides Similar Health-Related Quality of Life but Can Cause More Lumbar Disc and Facet Joint Degeneration: A Comparison of Adolescent Idiopathic Scoliosis Patients With Normal Population 10 Years After Surgery. Spine Deform. 2015;3(5):469-75. (doi:10.1016/j.jspd.2015.07.001).

29. Ohashi M, Bastrom TP, Marks MC, Bartley CE, Newton PO. The Benefits of Sparing Lumbar Motion Segments in Spinal Fusion for Adolescent Idiopathic Scoliosis Are Evident at 10 Years Postoperatively. Spine (Phila Pa 1976). 2020;45(11):755-63. (doi:10.1097/BRS.0000000000003373).

30. De la Garza Ramos R, Goodwin CR, Abu-Bonsrah N, et all. Patient and operative factors associated with complications following adolescent idiopathic scoliosis surgery: an analysis of 36,335 patients from the Nationwide Inpatient Sample. J Neurosurg Pediatr. 2016;25(6):730-6. (doi:10.3171/2016.6.PEDS16200). 